\title{
Short Segment Conduction Study and Localization Features in Ulnar Neuropathy at the Elbow: A Retrospective Study of 57 Patients
}

\author{
Pelin YILDIRIM', Tuğçe ÖZEKLi MISIRLIOĞLU², Abdullah YILDIRIM³, Gökhan EVCiLi', Osman Hakan GÜNDÜZ5 \\ ${ }^{1}$ Clinic of Physical Medicine and Rehabilitation, Kocaeli Derince Training and Research Hospital, Kocaeli, Turkey \\ ${ }^{2}$ Clinic of Physical Medicine and Rehabilitation, Kocaeli State Hospital, Kocaeli, Turkey \\ ${ }^{3}$ Clinic of Plastic Esthetic and Reconstructive Surgery, Kocaeli, Turkey \\ ${ }^{4}$ Clinic of Neurology, Kocaeli Derince Training and Research Hospital, Kocaeli, Turkey \\ ${ }^{5}$ Department of Physical Medicine and Rehabilitation, Marmara University Faculty of Medicine, Istanbul, Turkey
}

\begin{abstract}
Objective: The aim of this study was to investigate the localization properties in electrodiagnostically evaluated patients with a prediagnosis of ulnar neuropathy at the elbow.

Material and Methods: The results of 57 patients who were electrodiagnostically defined as ulnar neuropathy at the elbow, with using short segment conduction study (SSCS), were evaluated retrospectively. The number of extremities determined as having focal conduction block with changes in latency was 30, while focal conduction alone was 27 . The locations of nerve entrapment sites were determined as humeroulnar arcade (HUA), retroepicondylar groove (RTC), medial intermuscular septum (MIS).

Results: The entrapment was found in the left upper extremity with a rate of $73 \%$. The frequencies of localizations were determined for RTC (35\%), MIS (25\%), RTC+MIS (19\%), HUA (16\%), HUA+RTC (5\%).

Conclusion: The entrapments at RTC, MIS and HUA regions could be determined in patients whom $10 \mathrm{~cm}$ SCSS technique was used. The localizations of ulnar nerve entrapment at the elbow were RTC, MIS and HUA, in the order of decreasing frequency.

Keywords: Ulnar neuropathy, short segment conduction study, elbow, cubital tunnel syndrome, entrapment neuropathies, electromyography
\end{abstract}

\section{Introduction}

Ulnar neuropathy at the elbow (UNE) is the second most frequently observed entrapment neuropathy in the upper extremity after the median nerve (1). The mean annual incidence is 24.7 per 100.000 people (2).

Developments and innovations recorded with electrodiagnostic techniques are useful for the accurate determination of
UNE localization. Sensory nerve conductions recorded from the $5^{\text {th }}$ finger by stimulating from the wrist or motor nerve conductions recorded by stimulating from three points (wrist, below the elbow, and above the elbow) are not sensitive enough to determine UNE localization $(3,4)$. Short segment conduction study (SSCS) is a technique that is used for localizing entrapment through the course of the nerve and is increasingly be- 
coming more common. It has played a role in the increase of diagnostic sensitivity $(5,6)$. Latency differences in short segments and reference values of conduction velocity have been revealed in a study conducted recently (7). A detailed electrophysiological examination including SSCS, in patients with UNE can influence the decision of conservative or surgical treatment and the technique of surgical treatment to be applied (8).

Changes in lifestyle, which lead to recurrent flexion of the elbow and occur with recently improving technology (increasing use of mobile phones, tablet computers and applications, computer games, etc.), have caused an increase in the frequency of UNE (9). It is thought that UNE mostly develops in the humeroulnar arcade (HUA) and/or retroepicondylar groove (RTC) $(8,10-12)$. In addition, to our knowledge, there is no study conducted after these technological developments, in which the frequency of UNE localizations has been investigated.

The aim of this study was to examine the frequency of UNE localizations using the recent reference values that have been revealed retrospectively and the SSCS technique.

\section{Material and Methods}

\section{Electrodiagnostic Study}

The data of 57 patients (among 92 patients) who were evaluated with the pre-diagnosis of ulnar neuropathy in the electroneuromyography (ENMG) laboratory and who were consistent with UNE were used, and the results were retrospectively examined. The ethics committee approval for the study was received from Kocaeli University.

The study included patients whose differential diagnosis of cervical radiculopathy and/or brachial plexopathy was made based on clinical examinations and whose pre-diagnosis was UNE. The patients who had atrophy and remarkable muscle strength loss in the intrinsic muscles and required a needle electromyography (EMG) study and those who had the electrodiagnostic findings of polyneuropathy were excluded from the study. All electrodiagnostic studies were conducted by the same researcher (P.Y.). Nihon Kohden MEB-9400K (Nihon-Kohden Corp, Tokyo, Japan, 2011) system was used in the study. For motor conduction studies, the filter settings were adjusted between $20 \mathrm{~Hz}$ and $10 \mathrm{kHz}$, stimulation frequency was $1 \mathrm{~Hz}$, and the duration of stimulation was $0.2 \mathrm{msn}$. For sensory conduction studies, the filter settings were between $20 \mathrm{~Hz}$ and $2 \mathrm{kHz}$, stimulation frequency was $1 \mathrm{~Hz}$, and the duration of stimulation was $0.2 \mathrm{msn}$. During the procedure, the room temperature was maintained at approximately $25^{\circ} \mathrm{C}$, and the skin temperature was maintained between 31 and $34^{\circ} \mathrm{C}$.

In the median motor conduction study, the recording was made from the abductor pollicis brevis. Distal latency, amplitude, and nerve conduction velocity values were calculated. The median and ulnar sensory conductions were antidromically recorded from the $3^{\text {rd }}$ and $5^{\text {th }}$ fingers, respectively. For the ulnar motor response, the recording was made from the abductor digiti minimi muscle, and distal latency, amplitude, and nerve conduction velocity were subsequently calculated by stimulating the wrist and below the wrist.
SSCSs were performed when the shoulder was in abduction and external rotation and the elbow was in 70-90 degrees of flexion. The middle point of the line on the ulnar groove between the olecranon and medial epicondyle was taken as the reference point. In addition, points $4 \mathrm{~cm}$ distal and $6 \mathrm{~cm}$ proximal to this point were marked with $2 \mathrm{~cm}$ intervals. For preventing distal spread and stabilizing stimulation at a specific point, supramaximal stimulation and adequate pressure were applied (4). According to this, five short segments were obtained: first segment: $4 \mathrm{~cm}$ distal to the elbow-2 cm distal to the elbow; second segment: $2 \mathrm{~cm}$ distal to the elbow-the elbow; third segment: the elbow-2 cm proximal to the elbow; fourth segment: $2 \mathrm{~cm}$ proximal to the elbow $-4 \mathrm{~cm}$ proximal to the elbow; and fifth segment: $4 \mathrm{~cm}$ proximal to the elbow- $6 \mathrm{~cm}$ proximal to the elbow (7).

The compound muscle action potential (CMAP) was recorded from the abductor digiti minimi muscle. Latencies were calculated from the beginning of the stimulation to the beginning of the CMAP, and amplitudes were calculated from the middle line to the negative peak. Latencies and amplitudes were recorded for the five segments mentioned above.

Electrodiagnostic studies of 96 upper extremities of 92 patients were performed with the SSCS technique routinely applied in our electrodiagnosis laboratory and with the technique explained above. In addition, they were retrospectively re-evaluated with reference values that were recently revealed. Based on this evaluation, for latency change, the values above $0.5 \mathrm{msn}$ in the $1^{\text {st }}, 4^{\text {th }}$, and $5^{\text {th }}$ segments; above $0.6 \mathrm{msn}$ in the $2^{\text {nd }}$ segment; and above $0.7 \mathrm{msn}$ in the $3^{\text {rd }}$ segment were accepted to be significant (7). For amplitude change, a decrease over $20 \%$ was interpreted in favor of focal conduction block, as recommended by the American Association of Neuromuscular and Electrodiagnostic Medicine (13).

\section{Anatomic Naming}

In this study, the entrapments in the medial epicondyle distal were considered as HUA lesions (cubital tunnel syndrome), which was the terminology used by Campbell (14). The entrapments in the immediate proximity of the medial epicondyle were evaluated as RTC, and the ones $\geq 2 \mathrm{~cm}$ proximal were evaluated as the medial intermuscular septum (MIS) entrapment (15).

In the results based on latency and amplitude changes, the classification of entrapments was performed as HUA when abnormal conduction was in the $1^{\text {st }}$ and $2^{\text {nd }}$ segments, as RTC when it was in the $3^{\text {rd }}$ segment, and as MIS when it was in the $4^{\text {th }}$ and $5^{\text {th }}$ segments $(14,15)$.

\section{Statistical Analysis}

For statistical analysis, the Statistical Package for the Social Sciences 15.0 (SPSS, Inc., Chicago, IL, USA) for Windows software was used. Descriptive statistics were presented as number and percentage for categorical variables and as mean, minimum, and maximum values for numerical variables. 


\section{Results}

Of 96 upper extremities of 92 patients, 57 (the mean age $42 \pm 10.9$ years) were found to be consistent with UNE. Of these patients, 32 were female and 25 were male. Entrapment was detected in the left upper extremity at the rate of $73 \%$.

Pathological findings obtained from SSCSs and including latency and amplitude changes are given in Table 1 and Table 2. All the electrophysiological findings are presented in Table 3.

\begin{tabular}{|c|c|c|c|c|}
\hline & Min. & Max. & M. & SD \\
\hline HUA - $1 \quad(n=2$ & 0.51 & 0.74 & 0.62 & 0.16 \\
\hline HUA - $2(n=9)$ & 0.62 & 1.82 & 0.85 & 0.35 \\
\hline $\operatorname{RTC}(n=29)$ & 0.70 & 1.88 & 0.96 & 0.29 \\
\hline MIS - $1(n=21)$ & 0.50 & 1.36 & 0.71 & 0.24 \\
\hline MIS - $2(n=2)$ & 0.72 & 1.56 & 1.14 & 0.59 \\
\hline
\end{tabular}

HUA - 1, humeroulnar arcade - 1: $4 \mathrm{~cm}$ distal to the elbow-2 cm distal to the elbow; HUA - 2, humeroulnar arcade - 2: $2 \mathrm{~cm}$ distal to the elbow-the elbow; RTC, retroepicondylar groove: the elbow $-2 \mathrm{~cm}$ proximal to the elbow; MIS - 1 , medial intermuscular septum - 1: $2 \mathrm{~cm}$ proximal to the elbow $-4 \mathrm{~cm}$ proximal to the elbow; MIS - 2, medial intermuscular septum - 2: $4 \mathrm{~cm}$ proximal to the elbow $-6 \mathrm{~cm}$ proximal to the elbow; Min: minimum; Max: maximum; M: mean; SD: standard deviation

Table 2. The values of pathological amplitude difference (\%) in short segments

\begin{tabular}{lcccc} 
& Min. & Max. & M. & SD \\
\hline HUA - 1 $(n=1)$ & 21.2 & 21.2 & 21.2 & - \\
HUA - 2 $(n=4)$ & 25.1 & 47.7 & 32.3 & 10.3 \\
RTC $(n=15)$ & 20.1 & 41.7 & 28.6 & 6.1 \\
MIS - 1 $(n=9)$ & 22.6 & 78.2 & 37.3 & 18.7 \\
MIS - 2 $(n=2)$ & 21.6 & 22.3 & 21.9 & 0.5
\end{tabular}

HUA - 1, humeroulnar arcade $-1: 4 \mathrm{~cm}$ distal to the elbow-2 cm distal to the elbow; HUA - 2, humeroulnar arcade $-2: 2 \mathrm{~cm}$ distal to the elbow-the elbow; RTC, retroepicondylar groove: the elbow $-2 \mathrm{~cm}$ proximal to the elbow; MIS - 1, medial intermuscular septum - 1: $2 \mathrm{~cm}$ proximal to the elbow $-4 \mathrm{~cm}$ proximal to the elbow; MIS - 2, medial intermuscular septum - 2: $4 \mathrm{~cm}$ proximal to the elbow- $6 \mathrm{~cm}$ proximal to the elbow; Min: minimum; Max: maximum; M: mean; SD: standard deviation
Table 4. Distributions of UNE with latency change accompanied by focal conduction block and with only latency change

\begin{tabular}{lcc} 
& $\begin{array}{c}\text { Latency change and } \\
\text { focal conduction block }\end{array}$ & $\begin{array}{c}\text { Latency } \\
\text { change }\end{array}$ \\
\hline Number of extremities & 30 & 27 \\
Age (m, min-max) & $39(21-64)$ & $44(23-70)$ \\
Gender (F, \% / M, \%) & $17(57) / 13(43)$ & $15(55) / 12(45)$ \\
Right / Left (n, \%) & $8(27) / 18(73)$ & $7(26) / 23(74)$ \\
HUA (n, \%) & $4(15)$ & $5(18)$ \\
RTC (n, \%) & $8(30)$ & $12(44)$ \\
MiS (n, \%) & $8(30)$ & $6(23)$ \\
HUA+RTC (n, \%) & $1(3)$ & $2(7)$ \\
RTC+MIS (n, \%) & $6(22)$ & $5(18)$ \\
\hline
\end{tabular}

UNE: ulnar neuropathy at the elbow; HUA: humeroulnar arcade; RTC: retroepicondylar groove; MIS: medial intermuscular septum; HUA+RTC: entrapment in humeroulnar arcade and retroepicondylar groove together; RTC+MIS: entrapment in retroepicondylar groove and medial intermuscular septum together; F: female; M: male

\section{Table 5. Localization features of UNE}

\begin{tabular}{|c|c|c|c|c|c|}
\hline & \multicolumn{2}{|c|}{ Female } & \multicolumn{2}{|c|}{ Male } & \multirow{2}{*}{$\begin{array}{l}\text { Total } \\
\mathrm{n}=57\end{array}$} \\
\hline & $\underset{n=8}{\text { Right }}$ & $\begin{array}{c}\text { Left } \\
n=24\end{array}$ & $\begin{array}{c}\text { Right } \\
\mathrm{n}=6\end{array}$ & $\begin{array}{c}\text { Left } \\
\mathrm{n}=19\end{array}$ & \\
\hline HUA (n, \%) & $\begin{array}{c}0 \\
(0)\end{array}$ & $\begin{array}{c}5 \\
(21)\end{array}$ & $\begin{array}{c}2 \\
(33)\end{array}$ & $\begin{array}{c}2 \\
(10)\end{array}$ & $\begin{array}{c}9 \\
(16)\end{array}$ \\
\hline $\operatorname{RTC}(n, \%)$ & $\begin{array}{c}4 \\
(50)\end{array}$ & $\begin{array}{c}10 \\
(42)\end{array}$ & $\begin{array}{c}2 \\
(33)\end{array}$ & $\begin{array}{c}4 \\
(21)\end{array}$ & $\begin{array}{c}20 \\
(35)\end{array}$ \\
\hline MIS (n, \%) & $\begin{array}{c}4 \\
(50)\end{array}$ & $\begin{array}{c}4 \\
(16)\end{array}$ & $\begin{array}{c}1 \\
(17)\end{array}$ & $\begin{array}{c}5 \\
(26)\end{array}$ & $\begin{array}{c}14 \\
(25)\end{array}$ \\
\hline HUA+RTC (n, \%) & $\begin{array}{c}0 \\
(0)\end{array}$ & $\begin{array}{c}0 \\
(0)\end{array}$ & $\begin{array}{c}0 \\
(0)\end{array}$ & $\begin{array}{c}3 \\
(19)\end{array}$ & $\begin{array}{c}3 \\
(5)\end{array}$ \\
\hline RTC+MIS (n, \%) & $\begin{array}{c}0 \\
(0)\end{array}$ & $\begin{array}{c}5 \\
(21)\end{array}$ & $\begin{array}{c}1 \\
(17)\end{array}$ & $\begin{array}{c}5 \\
(26)\end{array}$ & $\begin{array}{c}11 \\
(19)\end{array}$ \\
\hline
\end{tabular}

UNE: ulnar neuropathy at the elbow; HUA: humeroulnar arcade; RTC: retroepicondylar groove; MIS: medial intermuscular septum; HUA+RTC: entrapment in humeroulnar arcade and retroepicondylar groove together; RTC+MIS: entrapment in retroepicondylar groove and medial intermuscular septum together

Table 3. All latency (msn) changes and amplitude $(\mathrm{mV})$ difference values in short segments $(\mathrm{n}=57)$

\begin{tabular}{|c|c|c|c|c|c|c|c|c|}
\hline & \multicolumn{4}{|c|}{ Latency } & \multicolumn{4}{|c|}{ Amplitude } \\
\hline & Min. & Max. & M. & SD & Min. & Max. & M. & SD \\
\hline HUA - 1 & 0.04 & 0.74 & 0.33 & 0.13 & -4.83 & 2.02 & -.6791 & 1.53108 \\
\hline RTC & 0.10 & 1.88 & 0.66 & 0.37 & -3.50 & 3.90 & .8808 & 1.79317 \\
\hline MIS - 1 & 0.14 & 1.36 & 0.51 & 0.27 & -2.90 & 3.99 & .8273 & 1.81266 \\
\hline
\end{tabular}

HUA - 1, humeroulnar arcade - 1: $4 \mathrm{~cm}$ distal to the elbow-2 cm distal to the elbow; HUA - 2, humeroulnar arcade - 2: $2 \mathrm{~cm}$ distal to the elbow-the elbow; RTC, retroepicondylar groove: the elbow-2 cm proximal to the elbow; MIS -1 , medial intermuscular septum $-1: 2 \mathrm{~cm}$ proximal to the elbow $-4 \mathrm{~cm}$ proximal to the elbow; MIS - 2, medial intermuscular septum - 2: $4 \mathrm{~cm}$ proximal to the elbow- $6 \mathrm{~cm}$ proximal to the elbow; Min: minimum; Max: maximum; M: mean; SD: standard deviation 
Although the number of extremities in which latency change with focal conduction block was detected was 30 , the number of extremities in which only conduction block was found was 27 (Table 4). In the evaluation of localization frequencies, RTC, MIS, RTC+MIS, HUA, and HUA+RTC were found as $35 \%, 25 \%, 19 \%$, $16 \%$, and $5 \%$, respectively (Table 5 ).

\section{Discussion}

In this study, the most common entrapment region of the ulnar nerve at the elbow was firstly RTC and then MIS. The least common region was HUA. It was observed that the number of patients diagnosed with focal conduction block that accompanied latency change was higher than the number of patients diagnosed only with latency change. In our study, it was detected that left dominance was available in patients with the diagnosis of UNE.

Electrodiagnostic tests can be restricted to the investigation of the accuracy of the pre-diagnosis established by a clinician or surgeon. Because the diagnostic value of routine motor conduction studies is lower, avoiding from standardized studies will keep patients away from unnecessary and disturbing procedures. The sensitivity of SSCS in the determination of UNE is similar to that of nerve conduction studies that are routinely performed, but its specificity is higher $(3,5,6)$. Therefore, in our study, nerve conduction studies performed with stimulation below and above the elbow were not preferred, and SSCS was applied instead of them. The results were re-evaluated retrospectively using new reference values detected in a large population.

The general view based on a few studies conducted on this issue is that the ulnar nerve is mostly entrapped in RTC and/or HUA $(8,10-12)$. Two studies are often reported as a basis for this information. In the study of Kanakamedala et al. (16), which was conducted on 13 patients, the rates of entrapment in RTC and HUA were reported as $62 \%$ and $28 \%$, respectively. In the study conducted by Campbell et al. (17), in which they used intraoperative electroneurography by saying that "it was good, but not perfect", the results were consistent with this study, and the entrapment rates of RTC and HUA were reported as $69 \%$ and $23 \%$, respectively. We assume that results different from those in our study may have resulted from the low number of patients in the first study and not using the SSCS technique, which has a high sensitivity and specificity in the detection of UNE, in both studies.

In the study of Kim et al. (18), which was published in 2003 , they retrospectively examined the surgical exploration results of a large population $(n=654)$, and they revealed that the most frequent region of lesion was the medial epicondyle proximal. The results of this study are similar to ours. However, it does not give a true opinion on the frequency of entrapment regions because it included ulnar nerve injuries such as gunshot injuries and lacerations to a large extent.

The entrapment of the ulnar nerve in the retroepicondylar groove and proximal was called as "tardy ulnar palsy", which is a terminology that is not often used currently. With the term "tardy", entrapments developing after a fracture or injury at the elbow was implied (19). From our point of view, rarity of this kind of etiologies caused a relatively high frequency of HUA entrapments. The term of entrapment also covers traction and friction that develop in the nerve as well as nerve dysfunction occurring because of the increased compression of the surrounding anatomical structures on the nerve. Compression, traction, and friction mechanisms lead to pathology in the formation of ulnar neuropathy (12). The products that have come into our lives with developing technology and that are becoming more common with long-term use require the elbow to be used with prolonged increased flexion. In a study conducted by Gelberman et al. (20), it was demonstrated that elbow flexion over 130 degrees increased intraneural pressure with traction mechanism. We assume that an increased frequency of entrapment in the MIS region occurs with the traction and stretching mechanisms in this region of the nerve. Although the extension in the proximity of the medial epicondyle can reach to $10 \mathrm{~mm}$ with the elbow flexion, the extension to the region distal to the medial epicondyle (in HUA) can be 3-6 mm $(21,22)$. Therefore, a more apparent extension that develops in the MIS region of the ulnar nerve with an increased elbow flexion causes this segment to remain relatively ischemic and the capacity to be stimulated is blocked. The reason for the increase in the frequency of neuropathy in the MIS region can be explained by this. On the other hand, RTC is the elbow region in which exposure to acute and chronic external compression is easier; therefore, the frequency rate of compression is higher. Moreover, recurrent subluxation of the ulnar nerve is one of the factors increasing UNE frequency in this region.

In the study of Visser et al. (5), which was conducted using SSCS in $2005(n=60)$, entrapment was detected in the region distal to the medial epicondyle in $40 \%$ of patients and in the retroepicondylar groove in 35\% of patients. SSCS was also used in this study, but it was applied with $8 \mathrm{~cm}$ technique instead of $10 \mathrm{~cm}$ technique. However, some of the MIS entrapments occur 4-6 $\mathrm{cm}$ proximal to the medial epicondyle and in the $5^{\text {th }}$ segment as in our study. Different results can be explained with this technical difference and also with that this study was conducted with a population in which technological applications requiring elbow flexion were not so common and not used in those years.

Focal conduction block is associated with the shorter duration of symptoms and younger age of patients (5). One of the potential weaknesses of our study is that the duration of symptoms was not investigated previously because of it being a retrospective study. UNE is a neuropathy that generally develops as acute (23). In acute compression neuropathies, the physiological response occurs as focal conduction block (24). In consistency with this situation, it was observed in our study that the number of patients determined with focal conduction block was higher than the number of patients diagnosed only with latency change.

In our study, UNE was detected in the left upper extremity at the rate of $75 \%$. Although this seems irrational considering that the dominant hand of most people is the right hand, other studies also confirmed this result. In fact, when the dominant hand is actively used, the non-dominant hand and elbow re- 
main in the flexion position for holding objects or for leaning on a fixed surface. Also, in the studies of Todnem et al. (12) and Visser et al. (5), the rates of the left upper extremities with UNE were $79 \%$ and $65 \%$, respectively.

Electrophysiological examination in association with the accurate detection of localization with SSCS is important for the elimination of other diagnoses, confirmation of pre-diagnosis, and choice of surgical treatment technique (8). In our study, anatomical naming of the area corresponding to the localization region that was determined with SSCS was used. In the previous studies conducted with the SSCS technique, the localization of entrapment in a $10 \mathrm{~cm}$ region proximal and distal to the elbow had been reported, but an exact anatomical definition had not been made.

UNE is a subject that has not reached a consensus with respect to its terminology. As is known, some researchers accept all UNE cases as "cubital tunnel syndrome" (25). On the other hand, for preventing confusion, some other researchers use the term "HUA" for the region that is anatomically corresponding to the "cubital tunnel" region, as in our study (8). Apart from that, there is no consensus on the entrapment regions. Campbell described four entrapment regions for the ulnar nerve at the elbow: MIS, RTC, HUA, and the exit point from the flexor carpi ulnaris (FCU) (18). On the other hand, according to Posner, there are five potential compression regions with the addition of the arcade of Struthers to the abovementioned regions (26). RTC is the region between the medial epicondyle and olecranon, HUA is approximately $3-25 \mathrm{~mm}$ distal to the medial epicondyle, and MIS starts from approximately $2 \mathrm{~cm}$ proximal to the medial epicondyle and extends on the upper arm $(15,18,26)$. The arcade of Struthers is a fibrous structure located $6-10 \mathrm{~cm}$ proximal to the medial epicondyle, and its existence was revealed in $70 \%$ of people (27). Entrapments in this region are quite rare. The exit point from $\mathrm{FCU}$ is another rare entrapment region, and it occurs 4-7 cm below the medial epicondyle (28). Because SSCS was applied in a $10 \mathrm{~cm}$ area in our study, the exit point from FCU and the arcade of Struthers were not evaluated. The entrapments $0-4 \mathrm{~cm}$ distal to the medial epicondyle were accepted as HUA, the entrapments $0-2 \mathrm{~cm}$ proximal to the medial epicondyle were accepted as RTC, and the ones $2-6 \mathrm{~cm}$ proximal were evaluated as MIS entrapments. Nevertheless, because all these anatomical regions are extremely close to each other, the distance should be specified in $\mathrm{cm}$ according to a reference point (medial epicondyle, etc.), and the term "approximately" should be used in the reports to avoid possible anatomical variations among people.

The retrospective feature of our study and relatively low number of patients are the limitations of our study. On the other hand, the use of new reference values for patients evaluated electrodiagnostically with SSCS has strengthened the results of our study.

\section{Conclusion}

The entrapment regions of the ulnar nerve at the elbow were RTC, MIS, and HUA according to the order of their fre- quency rates. The accurate detection of UNE localization can affect the treatment plan. The presence of focal conduction block that is revealed with SSCS and the effect of findings such as a localization region on the clinical symptoms can be determined with further prospective studies. Our study is important for the physician who diagnoses and the physician who plans the treatment to speak the same language in UNE for which different names are available for the same regions. Localization in UNE is clarified with electrodiagnostic evaluations and it should be clearly mentioned.

Ethics Committee Approval: Ethics committee approval was received for this study from the ethics committee of Kocaeli University.

Informed Consent: Due to the retrospective design of the study, informed consent was not taken.

Peer-review: Externally peer-reviewed.

Author Contributions: Concept - P.Y.; Design - P.Y.; Supervision H.G.; Resource - P.Y., T.O.M., G.E.; Materials - P.Y., A.Y.; Data Collection and/or Processing - P.Y., A.Y., T.O.M., G.E.; Analiz ve/veya yorum / Analysis and/or Interpretation - P.Y., A.Y.; Literature Review - P.Y., T.O.M., G.E.; Writer - P.Y., H.G.; Critical Review - H.G.

Conflict of Interest: No conflict of interest was declared by the authors.

Financial Disclosure: The authors declared that this study has received no financial support.

\section{References}

1. Merlevede K, Theys P, van Hees J. Diagnosis of ulnar neuropathy: a new approach. Muscle Nerve 2000;23:478-81. [CrossRef]

2. Mondelli M, Giannini F, Ballerini M, Gianneschi F, Martorelli E. Incidence of ulnar neuropathy at the elbow in the province of Siena (Italy). J Neurol Sci 2005;234:5-10. [CrossRef]

3. Azrieli $Y$, Weimer L, Lovelace R, Gooch $C$. The utility of segmental nerve conduction studies in ulnar mononeuropathy at the elbow. Muscle Nerve 2003;27:46-50. [CrossRef]

4. Beekman R, Van Der Plas JP, Uitdehaag BM, Schellens RL, Visser LH. Clinical, electrodiagnostic, and sonographic studies in ulnar neuropathy at the elbow. Muscle Nerve 2004;30:202-8. [CrossRef]

5. Visser LH, Beekman R, Franssen H. Short-segment nerve conduction studies in ulnar neuropathy at the elbow. Muscle Nerve 2005;31:331-8. [CrossRef]

6. Mesci E, Gunduz OH, Yagci I, Us O, Akyuz G. Sensitivites of various electrophysiological methods in the diagnosis of ulnar neuropathy at the elbow. Neurosurg Q 2010;20:60-4. [CrossRef]

7. Korkmaz $M$, On AY, Caliş FA. Reference data for ulnar nerve short segment conduction studies at the elbow. Muscle Nerve 2011;44:783-8. [CrossRef]

8. Landau ME, Campbell WW. Clinical features and electrodiagnosis of ulnar neuropathies. Phys Med Rehabil Clin N Am 2013;24:49-66. [CrossRef]

9. Darowish M, Lawton JN, Evans PJ. Q: What is cell phone elbow, and what should we tell our patients? Cleve Clin J Med 2009;76:306-8. [CrossRef]

10. Chimenti PC, Hammert WC. Ulnar Neuropathy at the Elbow: An Evidence-based Algorithm. Hand Clin 2013;29:435-42. [CrossRef] 
11. Assmus H, Antoniadis G, Bischoff C, Hoffmann R, Martini AK, Preissler $P$, et al. Cubital tunnel syndrome - a review and management guidelines. Cent Eur Neurosurg 2011;72:90-8. [CrossRef]

12. Todnem K, Michler RP, Wader TE, Engstrøm M, Sand T. The impact of extended electrodiagnostic studies in ulnar neuropathy at the elbow. BMC Neurol 2009;9:52. [CrossRef]

13. Practice parameter for electrodiagnostic studies in ulnar neuropathy at the elbow: summary statement. American Association of Electrodiagnostic Medicine, American Academy of Neurology, American Academy of Physical Medicine and Rehabilitation. Muscle Nerve 1999;22:408-11. [CrossRef]

14. Wehrli L, Oberlin C. The internal brachial ligament versus the arcade of Struthers: an anatomical study. Plast Reconstr Surg 2005;115:471-7. [CrossRef]

15. Campbell WW, Pridgeon RM, Riaz G, Astruc J, Sahni KS. Variations in anatomy of the ulnar nerve at the cubital tunnel: pitfalls in the diagnosis of ulnar neuropathy at the elbow. Muscle Nerve 1991; 14:733-8.

16. Kanakamedala RV, Simons DG, Porter RW, Zucker RS. Ulnar nerve entrapment at the elbow localized by short segment stimulation. Arch Phys Med Rehabil 1988;69:959-63.

17. Campbell WW, Pridgeon RM, Sahni KS. Short segment incremental studies in the evaluation of ulnar neuropathy at the elbow. Muscle Nerve 1992;15:1050-4. [CrossRef]

18. Kim DH, Han K, Tiel RL, Murovic JA, Kline DG. Surgical outcomes of 654 ulnar nerve lesions. J Neurosurg 2003;98:993-1004. [CrossRef]
19. Brickner WM. Late ulnar nerve palsy following elbow fracture in the adult. J Bone Joint Surg Am 1924;6:477-81.

20. Gelberman RH, Yamaguchi K, Hollstien SB, Winn SS, Heidenreich FP Jr, Bindra RR, et al. Changes in interstitial pressure and crosssectional area of the cubital tunnel and of the ulnar nerve with flexion of the elbow. An experimental study in human cadavera. J Bone Joint Surg Am 1998;80:492-501.

21. Szabo RM, Kwak C. Natural history and conservative management of cubital tunnel syndrome. Hand Clin 2007;23:311-8. [CrossRef]

22. Apfelberg DB, Larson SJ. Dynamic anatomy of the ulnar nerve at the elbow. Plast Reconstr Surg 1973;51:79-81. [CrossRef]

23. Herrmann DN, Preston DC, Mclntosh KA, Logigian EL. Localization of ulnar neuropathy with conduction block across the elbow. Muscle Nerve 2001;24:698-700. [CrossRef]

24. Gelberman RH, Rydevik BL, Pess GM, Szabo RM, Lundborg G. Carpal tunnel syndrome. A scientific basis for clinical care. Orthop Clin North Am 1988; 19:115-24.

25. Feindel W, Stratford J. Cubital tunnel compression in tardy ulnar palsy. Can Med Assoc J 1958;78:351-3.

26. Posner MA. Compressive ulnar neuropathies at the elbow: I. Etiology and diagnosis. J Am Acad Orthop Surg 1998;6:282-8.

27. Ochiai N, Honmo J, Tsujino A, Nisiura Y. Electrodiagnosis in entrapment neuropathy by the arcade of Struthers. Clin Orthop Relat Res 2000;:129-35. [CrossRef]

28. Campbell WW, Pridgeon RM, Sahni SK. Entrapment neuropathy of the ulnar nerve at its point of exit from the flexor carpi ulnaris muscle. Muscle Nerve 1988;11:467-70. [CrossRef] 